\title{
Coping with Digital Divide in Governance: A Nepalese Perspective of Civil Service Reform
}

\author{
Varun Amatya, Ph.D. Student, \\ National Institute of Development Administration (NIDA), Thailand \\ 118, Seri Thai, 10240, Bangkok, Thailand
}

Associate Professor Dr. Pairote Pathranarakul National Institute of Development Administration (NIDA)

Received: Apr. 5, 2021 Accepted: May 17, 2021 Online published: May 26, 2021 doi:10.5296/jpag.v11i2.18681

URL: https://doi.org/10.5296/jpag.v11i2.18681

\begin{abstract}
There is a growing trend for governments across the world, in order to improve the efficiency of their services to offer to their constituents to implement digital devices in the process of the governance process. The so-called 'e-services' include a number of essential measures for civil service institutions to create and manage information, technology, and communication.

Current work discusses the effectiveness of e-services as well as challenges implementing said services and suggests ways to overcome the possibility of creating a digital divide via such services. The case study relied on content analysis and a survey approach to generate data.

This study proposed that the omnipresent nature of the internet, as well as the dynamic use of digital devices, has the potential to mobilize the public service and aid digital beginners in its considerable capacity to access government services.

The general conclusion of this study is that e-government services are crucial for managing future problems as well as appropriately reacting to present and past instances to be able to lessen the digital divide.

With regard to the reduction of current and future inefficiencies, the cases of effectiveness, and the costs associated with potential outcomes fully support our findings.

We propose that certain issues in relation to e-services can be regulatory, legal, technical as well as certain procedural measures. Another aspect is the civil service personnel's education
\end{abstract}


in relation to said technology, as well as capacity building and continuous upgrading of the digital internet technology available to government officers and the general public.

Additionally, civil service reform in Nepal with the possibility of the digitization of documents and capacity building is of great concern.

Keywords: digital divide, e-service, digitization, capacity building, technology trend

\section{Introduction}

In less than 100 years our world has moved from considering electric lamps to be a luxury item to ubiquitous communication technology that serves as a vehicle for the yottabits of information exchanged by 59.5 percent of the global population. In the words of Thomas L. Friedman, the world has become flat, and one of the levelers has been the Internet technologies.

But it is not only companies and private individuals who are taking part in this internet digital revolution. Today governments are actively embracing this technology. This process is not limited to developed nations only; central and local governments in developing countries just like their wealthy counterparts are uploading critical information online, automating the so-called 'big data and interacting electronically with their citizens (Buddhacarya. \& Chattarje, 2019). No one can dispute the fact that the advent of new information and communication technologies (ICTs) has pointedly improved governments' abilities to collect, process, and distribute information (Kwon, 2015).

While preparing the national development plans Nepalese government just like its counterparts in other developing countries, esteems ICTs as an important factor.

The current paper discusses the topic which has received mammoth attention lately; i.e., the use of ICT and the gaps in the civil services for those constituents without adequate access to or proper knowledge of ICT, termed in the literature as the 'digital divide'.

Lately, i.e., the development of online services to the citizens e-tax, e-transportation or e-health has become quite popular; in this regard E-services by the government have been considered as an evolving discipline dealing, more than any other particular government service (Danish Dada, 2006).

The concept of digitization describes and evaluates the influences ICTs are having on the practice and management of civil service as well as the relationships between public servants and the population in general.

Likewise, the so-called bridging of the digital divide includes a sequence of necessary steps government agencies have to create and offer to ensure effective execution of the above-mentioned e-services to the public at large (Kafle, 2016).

There is a wide curiosity among citizens about the digital world. The reform is needed in traditional services to digitize the system to develop and expand public administration from bureaucracy to service provider in the form of digital shift (MoE, 2013). The past ten years have seen a record-breaking explosion of innovation in ICT. 


\subsection{The Problem Statement and Objective of the Study}

The civil service in Nepal is under restructuration from unitary central government to a federal model of three tiers and reform for better service to public doorsteps. The nature of service is permanent and most of the government services are using ICT as a vital factor for efficient and effective service to the people. The main objective of this study is to explore effective service delivery methods by means of ICT for civil service in Nepal. The study has focused on government effort to reduce and overcome the digital divide through careful planning and implementation in four key areas:

1. development of digital content,

2. training to integrate ICT-based materials in the administrative process,

3. design and installation of supporting network and power infrastructure, and

4. involvement of the stakeholders for enhancing delivery capacity.

\section{Review of Scholarship}

Because of the novelty of the concept, and the limited global experience in implementing models in the public sector, criticisms about the practices are often based on an inaccurate understanding of what it is (Pariyar, 2007). Perhaps the biggest misconception related to the digital divide is that it is simply a computer usage program that assumes handling these machines to civil service personnel may automatically cause a revolutionary change in the service sector. There are indeed some public supporters who focus primarily on infrastructure installation (Pandey, 2017). The government policy on digital Nepal has an integrated framework consisting of digital content development, trainer preparation, networking and power infrastructure development, and public sector capacity development (NPC, 2020).

The Constitution of Nepal deals with the civil service architecture stipulating that "all services or positions in the Government of Nepal, other than the services and positions of army officers or soldiers and of armed police and police personnel and such other services and positions are excluded by an Act from the civil service or positions thereof, shall be deemed to be the civil service or positions thereof" (Mainali, 2010). In the present situation, the government of Nepal has operated services by forming Health Service and Parliament Service and they are not mentioned in the Civil Service Act and Regulations. However, clause 16 of the Civil Service Act has clarified that those services are also Civil Service (Bhatta, 2008). The Act related to Civil service personnel adjustment has created an interim provision to settle federal, provincial and local civil service personnel issue till the federal civil service act and provincial act is formulated (CAN, 2010).

New trends have appeared in civil service in the present age concerning gradual increment in the number of civil personnel, increased involvement of scientists and technicians, expansion in the right of civil personnel, positive orientation from negativity, change in the concept of neutrality of the past and emphasis on moral and professional ethics (Kumar \& Bista, 2006).

All over the world, media coverage of the digital movement has tended to focus far more on the web-based online and offline services themselves and not enough on how they can be 
used to enhance the quality of services to the public (MoE, 2013). The web-based services, however, is but a vital tool that is only as useful as the content it can deliver and the ability of the user to utilize the content. The distribution of hardware to civil personnel may not in itself lead to any revolutionary changes in the digitization process in public service reform (NTA, 2010).

Our lives have been irreversibly altered by the emergence of internet digital technologies. No aspect of our lives has been left untouched, be it commerce, information access learning communication, or work. There is a consensus among experts that the future holds even more convergence of our lives and the technology, in areas we cannot even fathom today. (Pun, 2012). Over the last 20 years, the convergence of audio-visual signal and data has been constantly increasing and existing communication networks are making it possible to have all IP-enabled networks including Next Generation Networks (NGN).

In this respect, a government as a service provider via its civil service institutions is just beginning to utilize the unlimited possibilities the internet has to offer (Rabaiah \& Vandijick, 2009).

Today an ever-increasing growing percentage of internet access is via broadband connections, allowing private users and organizations to interconnect with each other across physical or logical networks, organizational boundaries, and even national borders (Rasaili, 2016). Because more and more individual, companies, organizations, and even governments cannot perform their day-to-day activities without a reliable connection to the internet, or what is popularly known as cyberspace, the volume of information has expanded in geometrical progression, growing beyond traditional traffic to include multimedia and other forms of data. There is an ever-increasing number of new programs, applications, and services that use the capabilities of ICT infrastructure (InfoDev, 2002).

At the same time with the brisk growth of the internet, the issue of network security has become an Achilles heel for policymakers and regulators worldwide. It has been estimated that when any given network is connected to the internet it is simultaneously connected to more than 50,000 unknown networks along with all their users (CIA, 2010).

Henceforth the creation of strong IP networks with the possibility of 4.66 billion active internet users increases the security threats beyond any analysis done for this situation just a decade ago. In this respect, there is a constant challenge of protection of services and the people's privacy from data theft, fraud, hacking attacks, cyber warfare, not to mention terrorist and anti-national activities (Pariyar, 2007). Cyber-attacks like those against systems controlling infrastructure have been only the subject of science fiction literature, yet today it is a reality with the possibility of overwhelming effect not only on the national economy but the global one as well. According to international estimates, "one in 295 emails is virus-infected and 3 in 100 emails carry malware" (Kwon, 2015).

According to Sophos Labs, there are 95,000 malware pieces every day in 2010, and this number has doubled just in one year. It is estimated that almost ninety percent of e-mails are spam, with more than 3500 malicious websites that are blocked on a daily basis. 
Additionally, $32 \%$ of the cyber-attacks are phishing, followed by $29 \%$ of viruses and $18 \%$ of network scanning or probing (CAN, 2010).

It is no coincidence therefore that cybersecurity has now become of utter importance, since the internet simply not be limited to provide vital services to citizens, but may also be used in malicious manner such as social engineering-a technique that encompasses psychological tricks used to persuade people to undermine their own online security (Pun, 2012). In recent years social engineering has been on the rise across all the social networks.

Social engineering may include such actions on behalf of ordinary un-suspecting internet users as downloading an email attachment, clicking on a link, or filling out a form with private or confidential information.

In brief cybercriminals across the world have a multitude of tricky scams up their sleeves to spread malware, utilize social engineering techniques, and abuse human desires and fears, as well as just plain human curiosity to get past the caution one would normally exercise when in cyber space (InfoDev, 2002).

Social networks with the support of modulated applications are coming up and expected to be one of the major sources of service efficiency effectiveness to common people in near future because of the access to the devices through cell phones and laptops. User-friendly social media may be vital in reducing digital gaps in the future. Since the introduction of smartphones more and more users get involved in online activities thus creating a potential shift in cyber access via mobile platforms, since as with other platforms, people would like to explore where the most users are. (Pandey, 2017). Cloud computing refers to a type of computing that relies on sharing computing resources rather than maintaining and supporting local servers. Currently cloud computing is a growing trend due to its considerable cost savings opportunities for organizations. This trend may help to provide more services in an efficient way (Satyanarayana, 2011).

Movement from a legacy network to a next-generation network may provide a platform for the development of many useful applications and sharing of information. The skills required by ordinary people are considerably reduced, thus for a person, it is much easier to use applications that can be accessed through the internet (InfoDev, 2002). Therefore, access to social networks continues to increase with a growing number of devices connected on the internet coupled with the popularity of easy-to-use operating systems and development environments. At the same time for organizations because of the anonymity of the internet the critical data that has personal data, critical enterprise resources, and others are a potential source of leverages to service expansion.

\subsection{IT Policy and Emerging Challenges of Digital Divide}

Nepalese National Planning Commission stipulates that "Policies are used to set a standard for performance and an organization can develop clear expectations for people of different profession and its administrators." (NPC, 2020). Policies provide a consistent framework for consistent actions regardless of location, or even country-wide. Likewise, Nepalese federal and provincial laws set a policy framework for the use of technology within the civil service 
system. Additionally, all Nepalese local and provincial governments are required to have technology plans in compliance with the federal Nepalese policies.

Once an institution establishes and follows clear-cut policies it can protect itself from litigation for non-compliance. Clear organizational guidelines that are implemented vertically and horizontally across an organization allow leaders of these organizations to steer away from legal troubles.

Information technology (IT) that includes various sectors such as education, health, agriculture, and tourism, give the world's least developed countries, including Nepal, an opportunity to rapidly develop trade and as a consequence economy.

Hence, it has become imperative for Nepal to formulate a viable policy for developing Information Technology to enhance the national economy (NTA, 2010).

Information Technology has to be created to have said technology readily accessible to the general public as well as to create employment opportunities through IT. Additionally, the aim of formulating IT policy is to build a knowledge-based society as well as to establish knowledge-based industries.

Many issues have to be resolved and challenges overcome before an e-government program can progress-all this depends on a specific country's economic, social, and technological reality. Some countries face low internet penetration, lack of IT literacy among the citizens, infrastructure restrictions, digital divide issues. Others have a limited number of qualified IT specialists, unavailability of payment gateway, lack of digital signature process and concerns regarding privacy and security. (MoE, 2013).

For the country of Nepal, IT policy is a noteworthy and vital step in the right path towards developing the ICT sector and the creation of the knowledge-based society, albeit several challenges have affected the country's labors aimed at establishing the initial momentum that it has achieved in the ICT sphere.

Overall, in Nepal, the digital opportunities have confronted a number of contending priorities that range from security challenges to poor governance as well as prevalent poverty. All this while the Nepalese government, while in the planning process, has continually expressed its desire to include the country into a knowledge-based society, (Rasaili, 2016).

The country of Nepal has failed to completely implement the IT policy and over the last few years' implementation of the IT, the policy has moved down from Nepal's government's priority list, due to the scarce resources tied up in security efforts.

Even though the institutional provisions have been put in place, as it turned out the key implementing body was significantly under-resourced to effectively oversee the implementation of the IT plan. Kumar \& Bista (2006) assert that the process of finalizing the IT policy was a long but inclusive one, albeit it is clear that e-services in Nepal are enhancing but still not fully developed.

Today the country of Nepal continues to have numerous problems that range from political 
and social instability, where funding for any project depends upon highly politicized and very limited government resources, which is why the problems persist for decades.

\subsection{Critical Infrastructure and Its Protection}

Today we take for granted products and services that only a hundred years ago were short of being a miracle. The infrastructure that is made up of the roads, airports, power plants, and communication facilities is so seamlessly integrated into our lives that we only notice it when it fails to operate the way were are used to (CIA, 2010).

Nevertheless, even if only a single of these systems is disrupted there could be dire consequences for the whole country, and perhaps even global ripple effects. Therefore, some elements of the infrastructure that are essential for operations of the country's economy and government at the minimum are termed as 'critical infrastructure' (Bhatta, 2008).

The critical infrastructure could mean the computers, computer systems, and/or networks, whether physical or virtual and/or the computer programs, computer data, content data, and/or traffic data. All of these are so vital to a country today that the inability or destruction of, or interference with such systems and data would surely have a shocking impact on security, economic prosperity, national public health, or any combination of those matters, similar to perhaps a nuclear attack by an enemy force (Buddhacarya. \& Chattarje, 2019).

Today many critical sectors of the county's economy and national security greatly depend on ICT and therefore it becomes an issue of paramount importance to protect these sectors from cyber threats from within as outside, as well as to reduce the digital divide among the citizens of the country (Kafle, 2016).

\section{Methodology}

The researcher has applied survey research to collect primary data from employees of government organizations, who provide services as front desk officers in various parts of the country. The researcher has designed a questionnaire that consists of information about demographics, physical facilities, ICT tools, and training, and public service delivery. The methods adopted are a review of recent literature, journals, and government documents. The data received were analyzed using statistical tools.

The researcher has adopted both quantitative and qualitative research techniques and collected the primary data from civil servants whose primary role is to deliver service for common people. The researchers have developed questionnaires that consist of information about demographics, physical facilities, ICT accessories, social networks, and MIS. Books, academic journals, government annual reports, and websites were also used for scholarly review.

\section{Results}

Primary data have been collected from civil servants' organizations. The total numbers of respondents were 384 from ministries, regional offices, departments, district-level offices, and local level governments at various part of the country. 


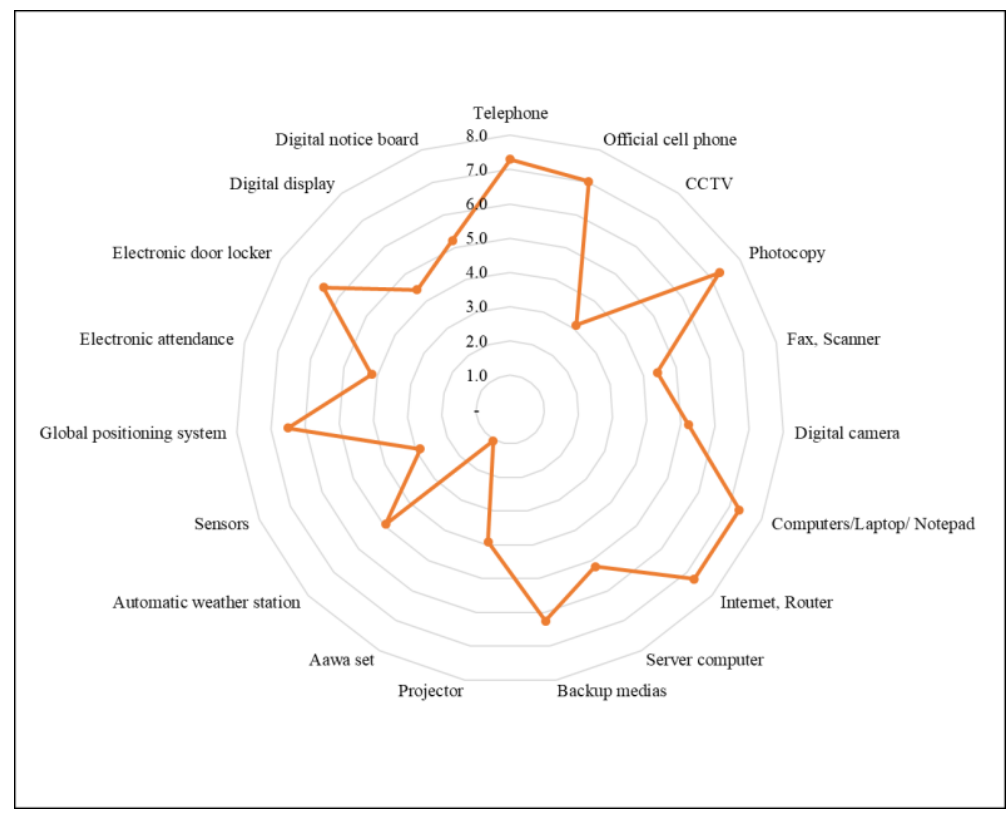

Figure 1. Use of Existing ICT Accessories by Respondents

Figure 1 describes the existing ICT accessories of the respondent office. To provide effective service to the common people ICT tools are being essential these days. It has shown that ICT accessories which are using in government organizations are not sufficient and equally used all over the country. The digital divide is widely visible while receiving the digital infrastructure in different parts of the country. The use of GPS, internet, photocopy, computers, and telephone are found more as compared to CCTV, digital display, and sensors.

The assessment of using social networks, software, and applications was carried out among the participants while concerning the digital divide. Among them, the digital divide was seen visible by the assessment through website, application software, Facebook, YouTube, Twitter, Skype, Instagram, and others including 17 tools of digital services. The gap has been found under the categories of assessing respondents of 384 from different parts of the country covering rural and urban settings. The front desk users of the civil service were on the assessment rating the use of this in basic purpose. 


\section{Macrothink}

Journal of Public Administration and Governance

ISSN 2161-7104

2021, Vol. 11, No. 2

Table 1. Capacity of respondents on the social network, software, and applications

\begin{tabular}{|c|c|c|}
\hline Social Network/ Software/ Apps & No. of Respondents & Percentage \\
\hline Website & 34 & 8.9 \\
\hline Application software & 41 & 10.7 \\
\hline Facebook & 67 & 17.4 \\
\hline Twitter & 10 & 2.6 \\
\hline Skype & 20 & 5.2 \\
\hline Instagram & 12 & 3.1 \\
\hline GPS & 11 & 2.9 \\
\hline Electronic calendar & 17 & 4.4 \\
\hline YouTube & 29 & 7.6 \\
\hline Date converter & 10 & 2.6 \\
\hline Font translator & 14 & 3.6 \\
\hline Viber & 21 & 5.5 \\
\hline Electronic dictionary & 12 & 3.1 \\
\hline WhatsApp & 12 & 3.1 \\
\hline Antivirus & 31 & 8.1 \\
\hline Firewall & 17 & 4.4 \\
\hline Data backup system & 26 & 6.8 \\
\hline Total & 384 & 100.0 \\
\hline
\end{tabular}

Source: Field Data, 2020

Table 1 describes the existing capacity of the social network, software, and apps at the respondent office. It shows that the organizations which are using the website, antivirus, data backup, application software, Facebook are more in number but are using a firewall, electronic calendar, GPS, Skype not satisfactory in government organization and varies in the different location of the country. The digital divide is seen in remote and rural as well.

Figure 2 shows the number of users and priority given to use the digital devices based on the availability of them with skilled human resources.

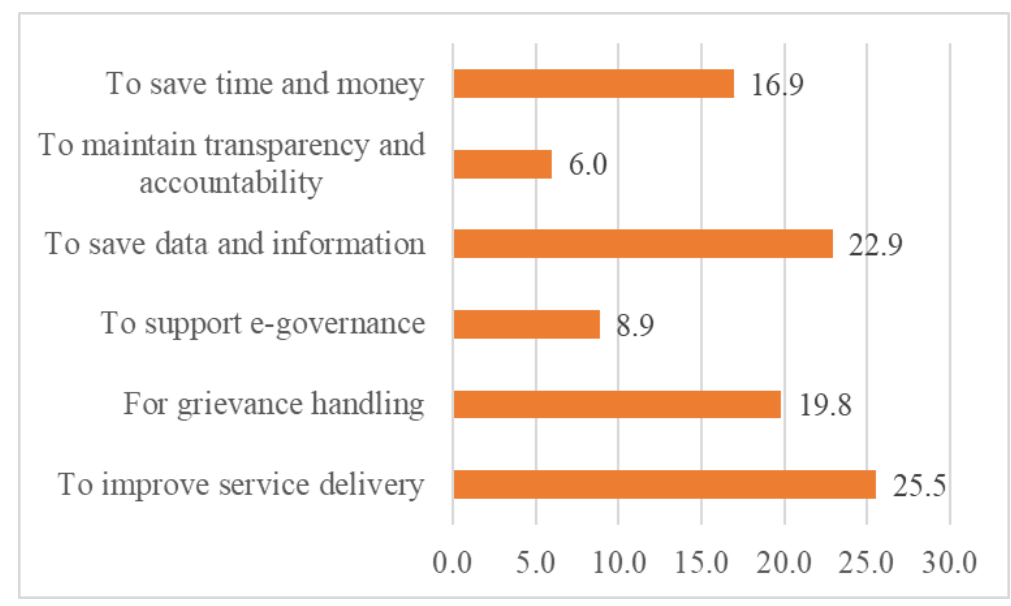

Figure 2. Percentage of respondents using MIS

Figure 2 describes the purpose of using the MIS in government organizations is for improving service delivery, grievance handling, save information as well as saving time and 


\section{Macrothink}

money, and maintaining transparency, accountability and support e-governance. The focus has been seen in improvements in service delivery with the highest percentage of $25.5 \%$, and to maintain transparency and accountability the least ones.

The challenges of the digital divide have been also found in using MIS with the problems to have greater access to the public through the skilled human resources, power back up, ICT infrastructure, lack of budget, user-friendly software, the influence of virus, and data security as shown in figure 3 .

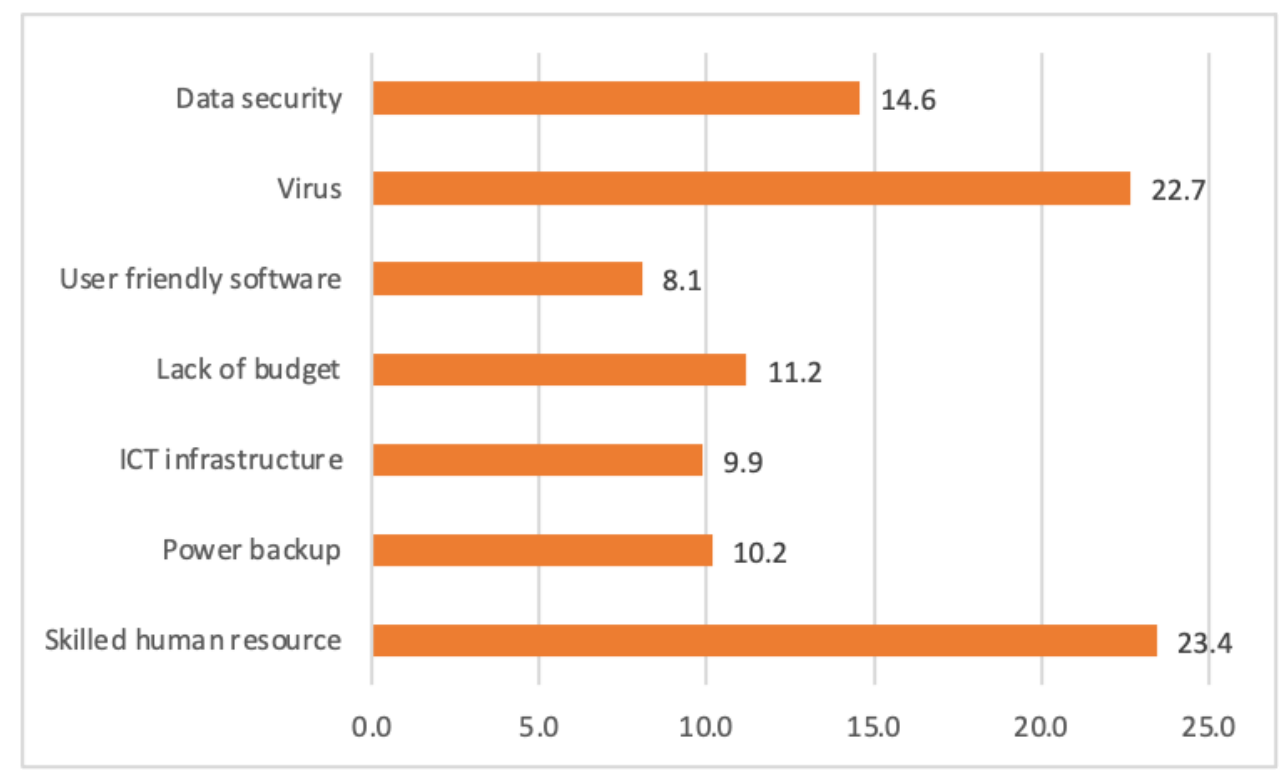

Figure 3. Challenges of Cooperation Management Information System

Figure 3 describes the importance of computer viruses, skilled human resources, and data security is being a great challenge for a government organization to reduce the digital divide. ICT infrastructure, lack of budget, user-friendly software and skilled human resources are the other challenges for implementing e-governance through the less emphasis given to them.

The respondents were assessed to have or not to have IT-related training. Figure 4 illustrates the respondents' answers under the category of 'yes' and 'no'.

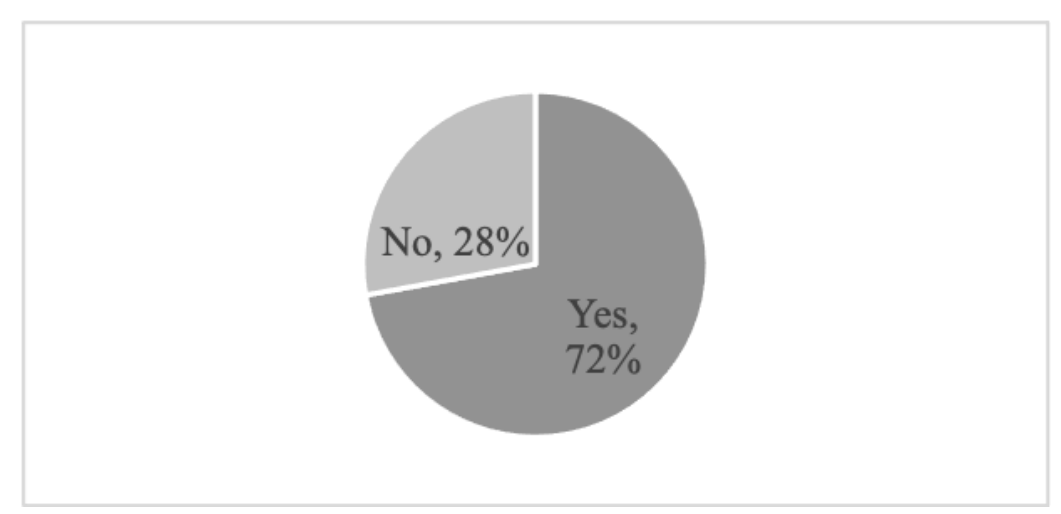

Figure 4. Response on the training of information technology (IT)

In the survey, shown as in figure $4,72 \%$ of the majority of respondents were asked whether 


\section{Macrothink}

they have joined any IT-related pieces of training and they agreed on this. Only $28 \%$ responded that they have not got training. The majority of the civil servants have got a chance to take training in IT. There is a less digital divide in this regard among the civil servants.

On the other hand, government institutions have continuously provided the training to their personnel in a diversified group of on-demand and nature of their works. Table 2 illustrates the training provided to office personnel in office package, database package, accounting package, IT management, email/internet service, networking, and social media use.

Table 2. Training provided to office personnel

\begin{tabular}{|c|c|c|}
\hline Types of Training & No. of Respondents & Percentage of Respondents \\
\hline Office package & 104 & 27.1 \\
\hline Database package & 65 & 16.9 \\
\hline Accounting package & 36 & 9.4 \\
\hline IT management & 26 & 6.8 \\
\hline Email, internet & 52 & 13.5 \\
\hline Networking & 23 & 6.0 \\
\hline Social media like Facebook, Twitter, etc. & 65 & 16.9 \\
\hline Multiple Packages & 13 & 3.4 \\
\hline Total & 384 & 100.0 \\
\hline
\end{tabular}

Source: Field data, 2020

Table 2 shows that the number of respondents who have taken office package-related training programs are in majority and only a few candidates took training in IT management, networking, and accounting packages. Some respondents have taken more than one training program.

The expertise in different software programs is assessed under the common service packages including MS Word, MS Excel, MS PowerPoint, MS Access, Tally, Photoshop and others. Figure 5 shows the results of capacity on operating the programs.

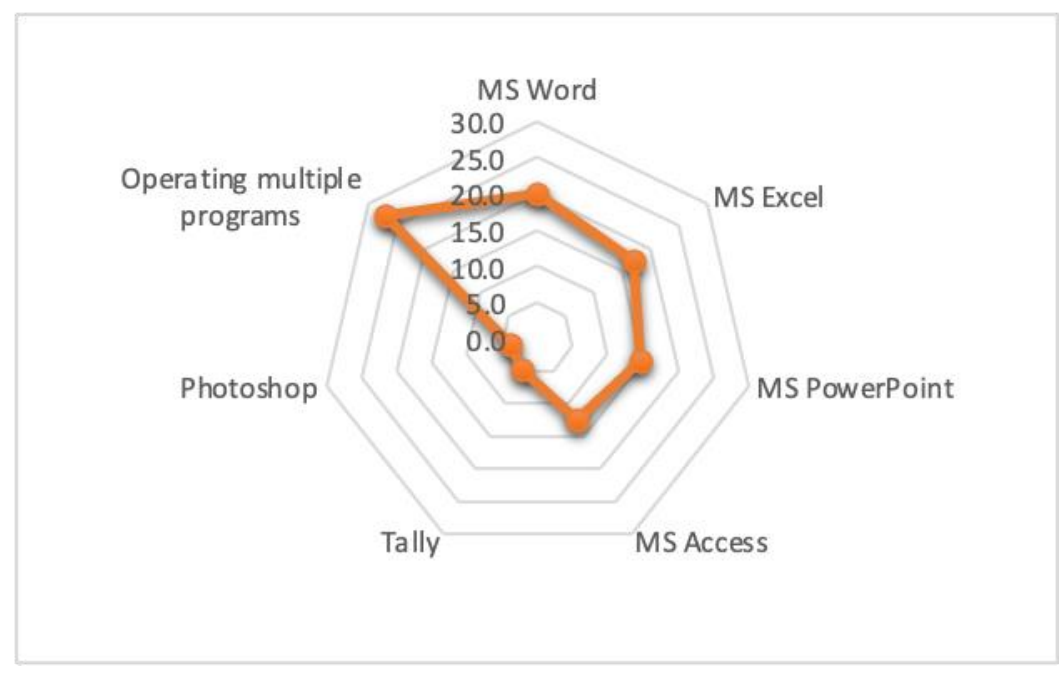

Figure 5. Capacity to Operate the Programs

Similarly, figure 5 shows the percentage of respondents out of 384 respondents' majority of 


\section{Macrothink}

Journal of Public Administration and Governance

ISSN 2161-7104

2021, Vol. 11, No. 2

them are from the category of having knowledge of multiple program handling capacity and also on MS PowerPoint as well as MS Word. The least response has been found in Photoshop and Tally.

While assessing IT equipment and their condition the respondents rated the level under excellent, good, average, weak, and very weak in range. Figure 6 shows the condition of the equipment.

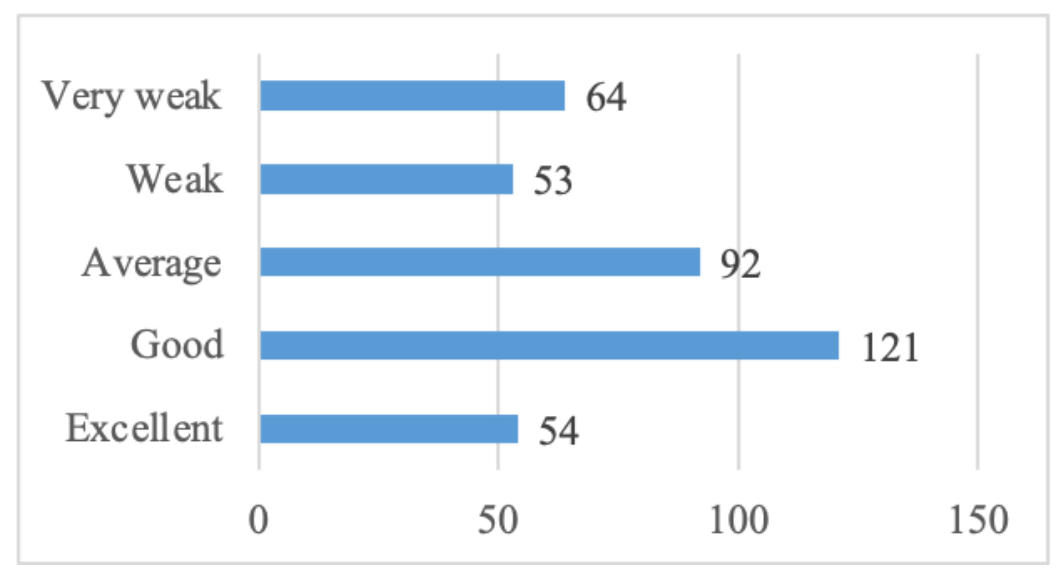

Figure 6. Rating the Condition of IT Equipment

Figure 6 demonstrates the status of the equipment in which the majority responded under good condition, the second majority on average. A minimum number responded for the weak and excellent condition of the equipment.

The digital divide has been assessed under the manual handling of services and digital handling of the services. The respondents reacted under manual service, digital service, partly digital service. Figure 7 shows the status of the digital divide situation in civil service.

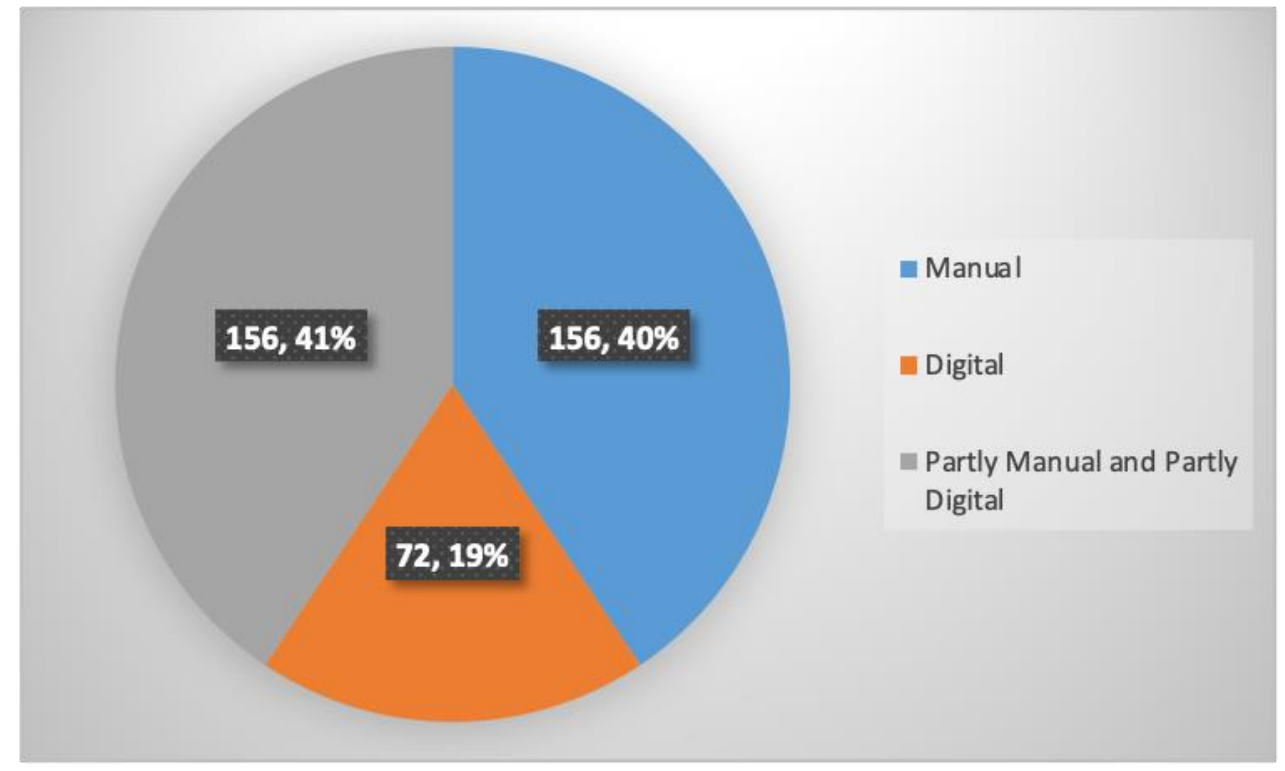

Figure 7. Preference of using equipment 
Figure 7 has shown that only $19 \%$ of respondents are capable to handle completely digital service and $41 \%$ have started partly digital and partly manual services. About $40 \%$ are still in manual services consuming more resources and delay in service provision.

The digital divide is quite visible and needs to be addressed under the reform program. The tests of significance of the differences between the population and sample means of the perceived response from the people as rated by the service providers, service seekers, and combined responses are illustrated in table 3 below:

Table 3. t-test results of the leadership behavior

\begin{tabular}{ccccc}
\hline Participants & Digital Divide Dimension & $\mathrm{t}$ & $\mathrm{d} \mathrm{f}$ & Sig.(two-tailed) \\
\hline Civil Servants & Complete Digital & 6.034 & 84 & 0.000 \\
& Partly Digital and Manual & 9.994 & 84 & 0.000 \\
Service Seekers & Complete Digital & -3.724 & 169 & 0.000 \\
& Partly Digital and Manual & -2.121 & 169 & 0.000 \\
Combined & Complete Digital & -1.425 & 254 & 0.156 \\
& Partly Digital and Manual & 1.229 & 254 & 0.220 \\
\hline
\end{tabular}

Source: Field Survey, 2020

The t-test results given in table 3 shows that the difference between the population mean and the sample mean of the civil servants' rating on their personal behavior is statistically significant at a $95 \%$ level of confidence. The difference between the digital service of respective civil servants perceived by the service seekers confirms that there is the significance of the difference but the combined perception indicates no difference in between the means for both complete digital and partly digital and manual dimensions of the service.

Thus, this survey result indicates that ICT-related general operational ability in the Civil servants is poor. It shows that only minority civil servants can operate the computer-based system easily. The government has to invest on reform fully ICT-based systems in its all units. There may need short course training programs to boost up their ICT knowledge. But proper infrastructure should be developed before making it mandatory.

\section{Discussion}

We would like to address the issue of the digital divide first, triage what problems need to be addressed, followed by an assessment which, if any, would the best technology to accomplish the task at hand more efficiently. We are constantly reminded that many projects fail at solving the problems because the technology, albeit good, is not the most appropriate or is not the most cost-effective solution.

We all need to consider that front-office, as well as back-office obstacles are considered in tandem in relation to appropriate technological solutions. This approach will certainly expand the number of issues that can potentially have an advantage from technology interventions. Prior to recommending technology to be used in solving a particular issue, one has to consider all necessary actions. 


\subsection{Adding Value}

Dealing with the problem of the digital divide, prior to recommending specific technology solutions, one has to make sure that that particular technological solution would add value to other solutions at the disposal of the policymakers.

Overall, there exist quite a number of various ways in which technology can add value. These dimensions including, but are not limited to expanding educational access to technology and the opportunity to utilize it, improving personnel level outcomes, and a variety of back-office undertakings that are prevalent in the developed countries today.

Regrettably, it is a challenge to locate the necessary comparative information on technology interventions, when it comes to developing countries' context, especially Nepal.

This fact, along with other knowledge gaps when it comes to technology use in developing countries, indicates that more intensive research is immediately required to evaluate and eradicate the issue of the digital divide.

\subsection{Sustainability}

It is of utter importance to prudently consider the full range of countrywide conditions while designing and implementing an intervention, which that may last over decades.

This includes, but is not limited to calculating the total cost of technology ownership, the ultimate relevance of the said technology to the particular site, access to suitable technological infrastructure, and last but not least human resource capacity of the location.

So often the federal government overlooks the local administrators, during the process of the introduction of the technology interventions, but these administrators are indispensable for sustaining the use of the said technology.

Scalability is another important but often overlooked issue. Administrators have to ask the poignant questions whether the intervention specific enough to satisfactorily address local problems and general enough to be scaled up to a district or regional level? Additionally, whether the practice will be pertinent and accessible with the passage of time, or whether external factors or lack of bearing will sooner or later lead those involved to abandon the said intervention?

\subsection{Multiple Uses}

It is important to determine that while a specific technology is selected and appropriate intervention is designed, whether these could be used for multiple purposes.

Such approach could certainly enable a higher number of persons to benefit from the technology. Additionally, it can also justify the unjustified start-up costs for such intercessions if they are used for a number of purposes.

For example, a computer lab in a university library should not only be reserved for university students' activities and catalog search but also be at the disposal for the training for the university instructors for enriching their work. It could also available to and local people for 
their own professional development or simply for informal learning.

\subsection{Lowest Cost and No Cost}

There exists a plethora of different technologies appropriate for a multitude of problems, but other things being equal, (as with anything else in life) it is best to select the least expensive option for the issue at hand or the locally developed technology that demands little or no cost at all. A more expensive option would bring little gains, especially in light of a reliable and cheaper option available at hand.

In no way are we advocating that quality should be sacrificed for the sake of lower cost. It goes without saying that a more expensive high-quality technology will last longer and cost less over time than a low-quality low-cost model that needs more frequent upgrades, repairs that could become obsolete in the near future.

At the same time, there are many examples when lower-cost devices achieve the same results as their more expensive alternatives. For example, when it comes to improving the service quality radio now is a much more cost-effective option than computers in many rural regions of developing countries. The bottom line is, if a lower-cost technology is readily available to solve a particular issue, it should certainly be used.

\subsection{Reliability}

Prior to technology deployment, those responsible for it have to make sure that it is reliable and will not break down before its average lifespan.

As part of the assessment of the reliability of technology, one has to make sure that such features as access to electricity or internet connectivity, presence of properly trained staff and maintenance personnel, options to update or upgrade said technology, are in place; all these associated and necessary elements, and of course are not limited to the above-mentioned items.

It goes without saying that the proposed technology needs to be adequately and appropriately examined by qualified personnel before it is established. These questions have to be honestly and impartially answered before technology is: Has the technology been used successfully in a similar environment or location? Is there a difference between rural and urban services? What were the challenges associated with this technology? If there were challenges, how have they been resolved? Did the technology break down or did it withstand constant use?

\subsection{Ease of Use}

Lastly, in public service interventions of reducing the digital divide, technology should be easy to use for ordinary citizens. According to the Technology Acceptance Model, the so-called 'perceived ease of use' gauge has been described to be among the three most important determining factors for technology uptake.

If extensive training is required to learn how to operate excessively complicated technologies this can in fact present barriers to implementation and the ultimate success of the intervention. 
As we have mentioned previously certain database applications require the use of sophisticated technical knowledge, and training to operate. While this is not to say that such applications should be completely eradicated, they should be carefully assessed.

On the other hand, when used appropriately these databases can be particularly useful for management purposes. Likewise, the relative ease of use should be considered before a digitization project is implemented to correctly assess whether or not, and what kind of, training is required.

Overall, all processes may guarantee that the technology is successfully and resourcefully utilized and save funds in the months and even years to come.

These basic guiding principles may help to steer away from many potential future problems and, more importantly, can help utilize the power of technology in reducing the digital divide in some of the poorest regions of the world like Nepal where people lack digital access and digital skills to apply technology for the betterment of their lives. With regard to the incessant speed of technological change, it is unlikely that the subject of technology in government service goes away anytime soon.

In our opinion, we are likely to see a plethora of new and creative ways for utilizing what good technology has to offer. Perhaps by 2025, a range of strategies of using digitals technologies will be created in the Global North that it has to share with the Global South.

\section{Conclusion and Way Forward}

Adopting new technology-based ICT tools in the civil service of Nepal effectively is being a challenge to us, for a long back. This is the main reason, civil service of Nepal not being as smart as required. On one side, the government has been spending a huge amount of budget on infrastructure and human resource development in the ICT sector. On other hand, ICT tools and applications existing in the workplace have not fully been utilized in service delivery. It shows that government is eager to share data and information, and government activities with its citizens but lack of positive attitude and devotion in civil servants, government resources, and skill of human resource are being misused. This paper concluded that through the adoption of the technology in the public administration (system) and implementation of the ICT tools and techniques in the civil service the government service delivery could become cheap, easy, and fast.

The ubiquitous nature of the internet can give aid to both the civil personnel and novice users alike due to its considerable capability to conduct effective and efficient service through e-governance. The consequence of implementing e-governance can ripple effects effect both for organizations (administrative) and individuals who seek a better quality of government services. For the government and public administrators alike supervising the technological risks means more locating hackers or setting up technological bridges to gap the digital divide. It is our opinion that the most serious negative consequences are sometimes due to pure negligence, weak capacity, poorly implemented technology, and ordinary mismanagement. 
No nation today should treat electronic media as an exclusive benefit for the privileged class, rather it should be for every one citizen of the country, therefore, bridging the digital divide, that side effect of the technological revolution.

Governments at all levels of the state should absolutely make sure that measures are taken to create a culture multidisciplinary approach to digital service and to halt the risk that information technologies will be used to deteriorate people's lives.

Nation-States, along with organizations, institutions and companies must have a strategic vision to minimize the digital divide and rather foster an information technology culture. Unquestionably various stakeholders must also be given the resources to understand, to learn, and to manage the technological, operational, and information-related problems they come across while using the ICT. In this respect, e-governance is essential in managing future services and responding to areas that might encounter digital divide problems. A few of the issues for consideration in relation to e-governance could be licensing and regulatory, technical and procedural measures as well as customer education and capacity building.

It could be that the restructuring of Nepal into a federal state has posed more challenges to the government as it tries to implement policies, plan and deliver efficient services to the general public, especially when it comes to new technology.

One of the major aspirations of the Nepalese people that there will come an ultra-modern technology-based service provider similar to providers in the developed countries.

\section{Some Implications to Future ICT Education}

The reality of our times is that the distractions of ever-expanding exposure to information and digital media have the potential to undermine the building of the basic and interdisciplinary platforms, so present-day educators need to be better than ever prepared to help learners of all ages to develop appropriate skills to use the technology and not the visa versa.

The most prominent feature of the cyber-world is that it places before people a multitude of ethical dilemmas, which are made even more complex by the apparent anonymity and ubiquity of the online experience.

Those individuals who are in want of effective and structured framework for dealing with such ethical dilemmas will surely find the worldwide web a place for potential self-harm, unable to make appropriate decisions to guide their actions very often with broader negative consequences for the society at large. It is, therefore, necessary for the governments, public administrators, and society at large to deal with the adverse consequences of the ICTs and encourage people to use online and offline digital services for the betterment of their lives.

The reality of our times is that those recent technological developments have given consumers easy access to a wide array of choices in almost all material domains of life. Henceforth if knowledge societies are to open access for people to this brave new world of ever-increasing choice, policymakers have to ensure that future university and even secondary school graduates are properly equipped with the applicable skills to effectively cope with it and carry the responsibility to reduce the digital divide in their localities. More 
often than not simple procedures, cost-effective devices, and quick service could attract all categories of people to the digital world, so that they could improve their own lives and those around them as well via ICTs.

\section{Acknowledgement}

The research is part of my Ph.D. dissertation towards an award of a doctor of philosophy degree, Development Administration from National Institute of Development Administration, NIDA

\section{References}

Bhatta, B. (2008). Civil Service of Nepal. Kathmandu: Makalu Publication.

CAN. (2010). National IT workforce survey 2005. Kathmandu: Computer Association of Nepal.

CIA (2010). The world fact book. Retrieved on March 8th, 2010 from https://www.cia.gov/library/publications/the-world-factbook/geos/np.html

Danish, D. (2006). A failure of e-government in developing countries: A Literature Review. EJISDC, 26(7), 1-10. https://doi.org/10.1002/j.1681-4835.2006.tb00176.x

InfoDev. (2002). The e-government handbook for developing countries - A project of InfoDev and the centre for democracy and technology. Centre for Democracy Technology. The World Bank.

Kafle, R. (2016). Good Governance: Evolution, Relevancy, Characteristics and Linkages. Swashasan. The journal or self-governance and rural development, 42, 28-35.

Buddhacarya, K., \& Chattarje, J. M. (2019). E-government in Nepal: The challenges in the implementation of the national identity card in Nepal. LBEF Research Journal of Science, Technology and Management, 1(2). ISSN: 2705-4683; e-ISSN: 2705-4748.

Kumar, R., \& Bista, M. L. (2006). Impact and Sustainability of e-government services in developing countries: Lessons learned from Tamil Nadu, India. Information Society, 22, I-12. https://doi.org/10.1080/01972240500388149

Kwon, G. H. (2015). Electronic government, e-government and e-policy. Graduate School of Governance, Sungkungkwan University.

Mainali, G. (2010). Administration reform: Theory, practice and training. Civil service journal, (3), 1.

MoE (2013). ICT Master Plan, Government of Nepal, Ministry of Education, Kathmandu, Nepal.

NTA (2010). Management information system. Report Vol. 32, Nepal Telecom Authority.

NPC (2020). Digital Nepal policy paper. Kathmandu: National Planning Commission.

Pandey, B. P. (2017). Challenges of the Grievance handling in Public Service Delivery and 


\section{Macrothink}

Journal of Public Administration and Governance ISSN 2161-7104 2021, Vol. 11, No. 2

the Use of Information Technology. PTA Journal, 1(5), 124-136.

Pariyar, M. P. (2007). E-government Initiatives in Nepal, Challenges and opportunities, ACM International Conference Proceeding Series; Vol. 232, Proceedings of the $1^{\text {st }}$ international conference on Theory and practice of electronic governance, Pp 280-282. https://doi.org/10.1145/1328057.1328115

Pun, M. (2012). Bridging the digital divide: The case of Nepal wireless. The Country Paper. Nepal Research and Education Network.

Rabaiah, A. \& Vandijick, E. (2009). A strategic framework of e-government: generic and best practice. Electronic journal of e-government, 7, 241-258. http://www.ejeg.com accessed date, 29 March, 2016.

Rasaili, B. (2016). E-government: From concept to service delivery. (Unpublished thesis)

Satyanarayana, J. (2011). E-government. p.22. New Delhi: PHI Learning Private Limited.

\section{Copyright Disclaimer}

Copyright for this article is retained by the author(s), with first publication rights granted to the journal.

This is an open-access article distributed under the terms and conditions of the Creative Commons Attribution license (http://creativecommons.org/licenses/by/4.0/). 